\title{
An age-representative exploration of pro-social behavior: human generosity-offerings, expectations, and fairness
}

\author{
Zoltan Szabo - Oliver Bela Kovacs - Gabor Murai - Zsofia Voros - Daniel Kehl \\ University of Pecs
}

\section{THE AIM OF THE PAPER}

Fairness and other-regarding preferences arguably are defining factors of the experiments conducted with dictator games, which provide an opportunity to examine the components of pro-sociality. Our analysis focuses on the experimental results suggesting that offerings and expectations are based on egalitarian behavior. Besides that, we attempted to explore the age-specific characteristics of hypothetical dictator games.

\section{METHODOLOGY}

We used survey data of an age-representative sample to measure how the results support previous research findings stating that generosity and its age-related aspects play a crucial role in the formation of human decisions and expectations.

\section{MOST IMPORTANT RESULTS}

Our results confirmed the dominance of hyper-fair behavior. However, significant differences were found across the dictator game variants in terms of the amounts of money marked. Subjects in cases of charity-offering, recipient-offering, and expectation give lower amounts on average compared to recipient-offerings and fairness, respectively. In contrast, the marked amounts are higher for recipient-offerings than for expectations with the absence of any significant age-effect.

Keywords: Pro-social behavior, Generosity, Dictator game, Aging, Offering, Expectation, Fairness

Acknowledgements: The project was financed by the European Social Fund: Comprehensive Development for Implementing Smart Specialization Strategies at the University of Pecs (EFOP-3.6.1.- 16-2016-00004). Declarations of interest: none.

DOI: 10.15170/MM.2021.55.KSZ.02.01 


\section{INTRODUCTION}

In the last decade, a new domain emerged in the literature on the characteristics, components, and influencing factors of decision-making. These analyses aim to shed light on the development of pro-social behavior in old age with scientific experiments. In the general characterization of decisions, wisdom appeared as a new aspect in addition to cognitive decline (Meeks \& Jeste 2009), offering new approaches to behavioral economists. A prerequisite for any substantive analysis is the identification of the components of wisdom that can be approached from both theoretical and experimental points of view. Previous research findings suggest that determinants of pro-social behavior such as altruism, trust, or reciprocity play an important role among these components (Meeks \& Jeste 2009, Lim \& Yu 2015). Although mainstream economic models were typically based on a uniform, purely self-directed view of man, the problem area of altruism and, in a broader sense, other-regarding behavior - referring in part to the relevant legacy of classical economics and in part to the sociological and anthropological literature of the era - also appeared relatively early in the mainstream economics (Becker 1974). However, Becker's (1974) study did not bring significant changes in mainstream economic models. The underlying reason could be partly the limited interpretation of the examined pro-social preferences and interactions, mainly as family processes, and partly the conclusions drawn from the microeconomic analyses of these interactions. On the contrary, the results of bargaining and cooperation experiments [primarily the ultimatum (Güth et al. 1982) and the dictator game (Kahneman et al. 1986, Forsythe et al. 1994) have already been a real challenge to the economic conception of the interpretation and role of self-interest.

Since our research relies on the results of hypothetical dictator games, we briefly outline the structure of the basic version of the dictator game, as well as some emphatic elements of theoretical debates regarding the first interpretations of the given results and their effects on subsequent experiments. In terms of its origins, the dictator game is a highly simplified version of the ultimatum game (Güth et al. 1982), intending to examine the selfish versus altruistic nature of decisions made by excluding any strategic considerations (Kahneman et al. 1986, Forsythe et al. 1994). Generally, the dictator game is a two-player game in which the bidder decides on the distribution of a certain amount between himself and the other party. This decision then finalizes and closes the game; the other party does not have a veto or other feedback options. For self-interested proposers, the rational decision would be to keep the total amount, which was not spectacularly justified by the first experimental results. For instance, in the case of allocating $10 \$$, the proportion of zero bids were only $21 \%$ (Forsythe et al. 1994).

Theoretical objections related to the conduct of the experiments and the interpretation of the given results and supported by experimental experiences drew attention to aspects that decisively influence the outcome of the game such as the anonymity (single vs. double-blind), the origin of the money to be distributed (earned vs. windfall money), or the context (distribution of a given amount of money vs. profit realization) (Hoffman et al. 1994, 1996, 2008, Smith 2010). Taking these critical observations into account, the rate of zero bids in the experiments conducted under earned money and double-blind conditions was 95-97\%, depending on the amount in the study of Cherry et al. (2002) while it was $100 \%$ in Oxoby \& Spraggon's (2008) analysis. As Vernon L. Smith states " $[\ldots]$ it is rare for people to walk around in the streets giving small amounts of their money to anonymous strangers" (Smith 2010, 12), making it clear that in a market economy context, the results of dictator games are not explicitly suitable to justify the role and significance of altruism.

A natural consequence of rejecting a strong generalization is the refinement of research programs and hypotheses, not reducing the importance of researches and laboratory experiments dealing with altruism or other components of pro-social behavior. From the results of several different types of experimental games (ultimatum game, trust game, public goods game, etc.) that examine the interactions between subjects and their consequences, we can conclude that manifestations of pro-social behavior not only play a meaningful role in understanding various social, but also in multiple, specifically economic phenomena (Fehr \& Schmidt 2006). Although the classical version of the dictator game is less suitable for studying interactions between participants, it has brought valuable results regarding the influencing factors of pro-social behavior, such as the role of social distance (Eckel \& Grossman 1996, Ball \& Eckel 1998, Harbaugh 1998, Bohnet \& Frey 1999a, 1999b, Brañas-Garza 2006, Fehr \& Schmidt 2006, Aguiar et al. 2008, Charness \& Gneezy 2008), or expectations on hyper-fair dictator-decisions (Brañas-Garza et al. 2017, 2018, Pereda et al. 2017).

While several variants of the different classical experimental games (ultimatum game, dictator 
game, trust game, public good game, etc.) have been developed for the analysis of pro-social behavior, the study of relevant peculiarities of old age decision-making rarely appeared among the research objectives (Lim \& Yu 2015). An excellent example of this is the dictator game, where Engel's meta-study (2011) on the development of decisions in old age is still one of the most commonly read references. There is no doubt that Engel's research (based on 616 experiments of 131 studies and the decisions of nearly 21,000 dictators) seeks to provide a comprehensive picture of the lessons of a quarter of a century of dictator games, including the extreme altruistic decisions of old age decision-makers. However, the study of decision-making in old age was not the main objective of any of the underlying studies. In addition, the proportion of elderly people among the experimental subjects was only $0.7 \%$. The results of dictator game experiments conducted since then (Roalf et al. 2012, Beadle et al. 2013, Rieger \& Mata 2015, Kettner \& Waichman 2016, Matsumoto et al. 2016, Ogawa et al. 2020) do not support the results of Engel's (2011) study in terms of the degree and some cases the existence of altruism in old age.

Within the framework of a research project at the University of Pecs, Faculty of Business and Economics entitled "Analysis of decision-making characteristics and influencing conditions in old age", we had the opportunity to place hypothetical dictator game questions in an age-representative questionnaire (Financial Decision Making 2020). The source of the hypothetical dictator-question examining altruistic behavior was Falk et al. (2018); in formulating the classic decision (windfall money, distribution task), we relied on the relevant experiments of Forsythe et al. (1994), and in the case of our question on expectations, BrañasGarza et al. (2017). The question of fair distribution is, in essence, one of the most important issues determining the creation and history of the dictator game since Güth et al. (1982), and in particular Kahneman et al. (1986) and Forsythe et al. (1994).

During the analysis, we sought answers to the following research questions:

RQ1: To what extent do the obtained results support the conclusion of Brañas-Garza et al. (2017) that generosity, and in a broader sense, egalitarian behavior, plays a crucial role in both subjects' decisions and their related expectations? In other words, how the distributions of offerings, expectations, and fairness develop relative to each other in the total sample?

RQ2: To what extent do the obtained results support the conclusion of Engel (2011) that age, especially old age, plays a crucial role in the formation of dictator-decisions. In other words, how the distributions of offerings, expectations, and fairness develop by age categories?

Based on the research questions above, we hypothesize the following:

Hypothesis 1. The hyper-fair behavior (equal split) is the modal charity- and recipient-offering, expectation, and marked value for fairness.

Hypothesis 2. The distributions of the variables charity- and recipient-offering, expectation, and fairness, each corresponding to a dictator game survey question, are stochastically the same in the total sample.

Hypothesis 3. The distributions of the variables charity- and recipient-offering, expectation, and fairness, each corresponding to a dictator game survey question, are stochastically different by distinct age categories.

Hypothesis 4. The distributions of the charityand recipient-offering, expectation, and fairness variable-pair differences are stochastically the same by distinct age categories.

\section{MATERIALS AND METHODS}

An age-representative survey with hypothetical dictator games was performed in 2020 by SocioGraph Market and Public Opinion Research Institute Ltd. in Hungary ${ }^{1}$. Respondents with no previous experience in bargaining games could answer the following questions voluntarily related to pro-sociality without receiving any kind of incentives.

SQ1. Offering (charity). Suppose that you unexpectedly receive 10,000 HUF. How much money would you donate from this amount to support a goal that you think is for a good cause? $(0-10,000$ HUF)

SQ2. Offering (recipient). Suppose that you and another randomly selected unknown subject participate in an experiment in which you receive 10,000 HUF without any obligation. You can decide how to distribute this amount between yourself and the other party. How much money would you donate to the other person? $(0-10,000 \mathrm{HUF})$

SQ3. Expectation. Suppose that you and another randomly selected unknown subject participate in an experiment in which the other party receives 10,000 HUF without any obligation. He / She can decide how to distribute this amount between himself / herself and you. How much money do you think the other person would donate to you? (0 10,000 HUF) 
SQ4. Fair distribution. Suppose that you and another randomly selected unknown subject participate in an experiment in which the other party receives 10,000 HUF without any obligation. $\mathrm{He} /$ She can decide how to distribute this amount between himself / herself and you. How much money would you consider fair to receive from the other person? $(0-10,000$ HUF $)$

Dictator game variants (SQ1-SQ4) were randomized for each respondent and placed as far apart as possible in the questionnaires to avoid framing. The database, compiled after processing the answers, contained 800 observations ( 389 males and 411 females; mean age $=47.46 \pm 16.75$ years). Due to the criterion of equal sample sizes, required in most of the applied statistical tests, we deleted the observations, where the respondent did not answer at least one dictator game question. As a result, the total sample involved in the analyses contained 770 observations ( 371 males and 399 females; mean age $=47.37 \pm 16.59$ years). See variables in Dataset A. 1 in Appendix A. Supplementary material. All statistical analysis and visualization were performed under the computing environment of the Stata/MP 13.0 software package. Subjects' answers were recorded only by their line numbers in the database to ensure complete anonymity. Association between decisions and names was never made. Data management was complied with the relevant data protection laws applicable in Hungary (in particular to the Act CXII of 2011 on the Right of Informational Self-Determination and on Freedom of Information and the General Data Protection Regulation (EU) 2016/679). The survey was carried out following the guidelines of the Hungarian Code of Professional Ethics of Psychologists and the applicable ethical principles (Code of Ethics) set out in the current university regulations, audited and approved by the Dean and the Disciplinary and Ethical Committee of the University of Pecs, Faculty of Business and Economics.

\section{RESULTS}

Descriptive statistics of the survey questions corresponding to the dictator games can be found in Appendix A. Supplementary material section (Table A.1). Figure 1 illustrates the amounts offered, expected, and considered fair, providing information about the shapes, variabilities, means, and medians of the distributions. In all four cases, the modal behavior was hyper-fair (equal split), confirming previous research findings. To test the second hypothesis, a one-way analysis of variance with repeated measures can be used to compare the distributions if the specific prerequisites (assumptions of normality and sphericity) are met. Based on the Shapiro-Wilk W test (Table A.2), the conditions of normality are violated. Hence, we implemented a non-parametric Friedman test on ranks $\left(X^{2}(3, N=\right.$ $770)=257.20, p<.0001) .{ }^{2}$ Based on the result, we can conclude that the four dictator game variants (in terms of the amounts of money provided) stochastically differ from each other at the 0.01 level of significance. As a post-hoc method, it is appropriate to compare each variable pair, for which paired sample t-tests may be suitable. In the present situation, due to the presence of nonnormality and the violation of the sphericity condition, a Nemenyi-Damico-Wolfe-Dunn test was used on the original variables for pairwise comparison instead (Table 1). Comparisons have lucid meaning only in variable-pairs SQ1-SQ2; SQ2-SQ3; SQ2-SQ4 and SQ3-SQ4. According to the test results, it can be concluded that the stochastic homogeneity ${ }^{3}$ does not exist for these cases; the distributions are stochastically different. 
Figure 1. Histograms of dictator game survey question variables. In every case, the hyper-fair behavior (i.e. the equal split in orange) is the modal choice. Pure selfishness (in lavender) and overall generosity (in cranberry) occur relatively few times. Significant differences can be observed across the dictator game variants.
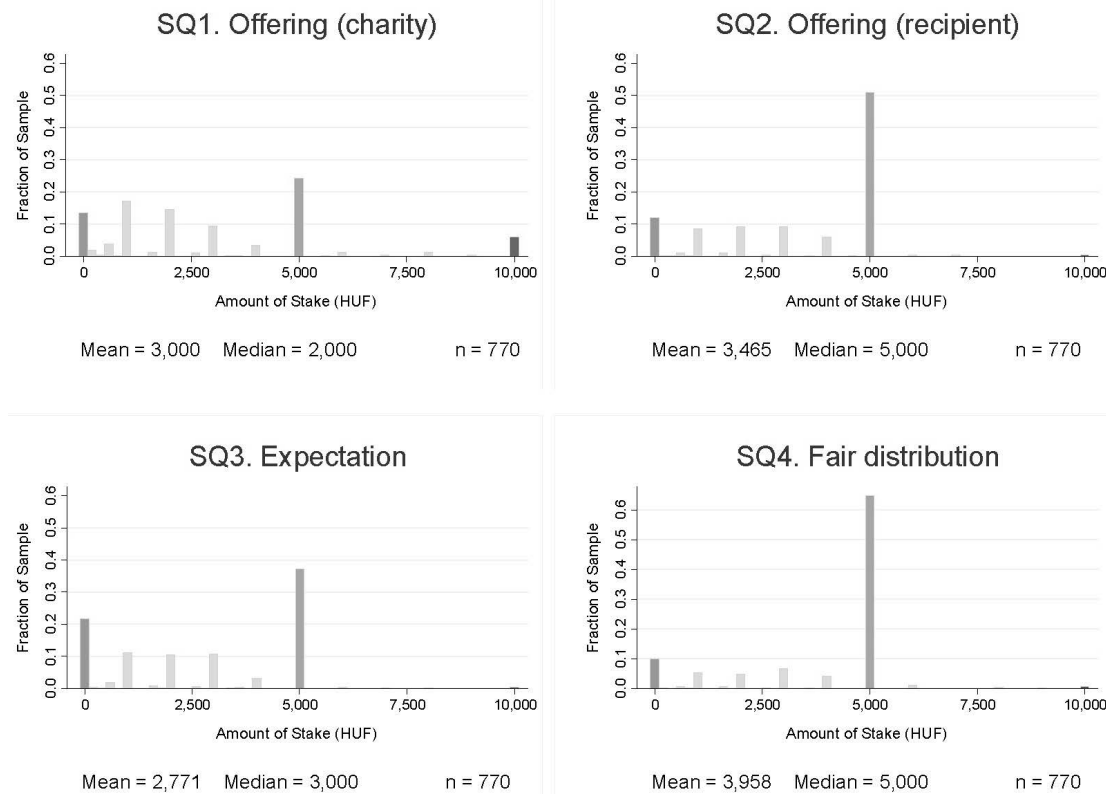

Source: own editing

Table 1. Pairwise comparisons of distributions by dictator game variants

\begin{tabular}{|c|c|c|c|}
\hline & SQ2. & SQ3. & SQ4. \\
\hline SQ1. & $0.0000^{* * *}$ & 0.6617 & $0.0000^{* * *}$ \\
\hline SQ2. & & $0.0000^{* * *}$ & $0.0001^{* * *}$ \\
\hline SQ3. & & & $0.0000^{* * *}$ \\
\hline
\end{tabular}

Note: No p-value correction is required for the Nemenyi-Damico-Wolfe-Dunn test. ${ }^{*} p<0.10,{ }^{* *} p<0.05,{ }^{* * *} p<0.01$

Source: own calculation

Although the second hypothesis formulated in the Introduction section is rejected, we used a multiple linear regression model to quantify each of the differences precisely while controlling for other variables at the same time. ${ }^{4}$ For this reason, a merged composite dependent variable was generated from the original dictator game survey ques- tion variables (see in Dataset A.2) (,6 $^{5}$ Explanatory dummy variables were also created by assigning a value of 0 or 1 to each observation based on the dictator game survey questions (e.g. the dummy variable SQ2 d, used as a regressor with the dependent variable C_SQ, assigns 1 to SQ2 observations and 0 to any other cases). Respondents' predicted 
amounts can be read from the Summary of linear regression analysis (Table A.4). Albeit the Shapiro-Wilk W test on residuals $(W(2340)=.99, p<$ .0001 ) indicated a significant departure from normality at the 0.01 level of significance, according to the central limit theorem, the violation of the normality assumption has no relevant consequence on the result obtained due to the sufficiently large sample size. The White test for heteroscedasticity $\left(X^{2}(90, \mathrm{~N}=2340)=195.24, p<.0001\right)$ showed that in most cases the sizes of the errors in our predictions significantly change across the values of the independent variables. To handle heteroscedasticity, we used robust standard errors (Table A.5). In addition, one can argue that the data are censored, thus we used a Tobit regression analysis with heteroscedasticity-robust standard errors (Table A.6). ${ }^{\text {? }}$ Our model $[F(14,2326)=12.15, p<.0001]$ as a whole fits significantly better than a model with no predictors at the 0.1 level of significance. The given values indicate that respondents in dictator variants charity-offering, recipient-offering, and expectation give lower amounts on average compared to recipient-offerings and fairness, respectively, while other control variables are taken into consideration. In contrast, subjects mark higher amounts for recipient-offerings than for expectations. Based on the corresponding p-values, regressors SQ2 d $(t=$ $2.76, p=.006), \mathrm{SQ} 3 \_\mathrm{d}(t=-2.14, p=.033), \overline{\mathrm{S} Q} 4 \_\mathrm{d}$ $(t=-6.44, p<.001)$ are significant predictors of the composite dependent variable at the 0.05 level of significance.

Despite the fact that age showed no significant effect in the regression analysis, 3 age categories were created ( 1 : ages $18-38, \mathrm{n}=251 ; 2$ : ages $39-59, \mathrm{n}=304 ; 3$ : ages $60-80, \mathrm{n}=215$ ) (see Dataset A.1). Figure 2 illustrates the cumulative distributions of dictator game questions, disaggregated by age categories. We used nonparametric James' second-order approximation tests on ranks to verify the related hypotheses. The differences between the ranked variable pairs were computed for each age category (see Dataset A.3). Based on the given test results (Table A.7), we found diversity in the distri- butions of the ranked variable-differences across age categories in contrast to the original ranked variables, where the distributions are stochastically the same between the age groups. Hence, further post-hoc procedures were applied only for the significant SQ2-SQ3 difference. According to the pairwise comparisons using Fligner-Polichello tests (Table 2), the stochastic homogeneity does not exist for the SQ2-SQ3_1_3 case at the 0.1 level of significance. We created a dependent variable merging SQ2-SQ3 differences of age categories 1 and 3 (see Dataset A.4), then used a Tobit regression analysis with heteroscedasticity-robust standard errors and control variables (Table A.9). ${ }^{8}$ The dummy variable age_cat_1_3_d assigns 1 to SQ2-SQ3 observations of age category 1 and 0 to SQ2-SQ3 observations of age category 3 . The model $[F(11,347)=1.74$, $p=.0644]$ as a whole fits significantly better than a model with no predictors at the 0.1 level of significance. However, the regressor age_cat_1_3_d $(t$ $=-0.63, p=.532)$ is not a significant predictor of the composite dependent variable at any common significance level. 
Figure 2. Cumulative distributions of dictator game survey question variables split by age. The distributions of the variables and variable-differences are stochastically the same between the predefined age categories except for the SQ2-SQ3_1 versus SQ2-SQ3_3 case.

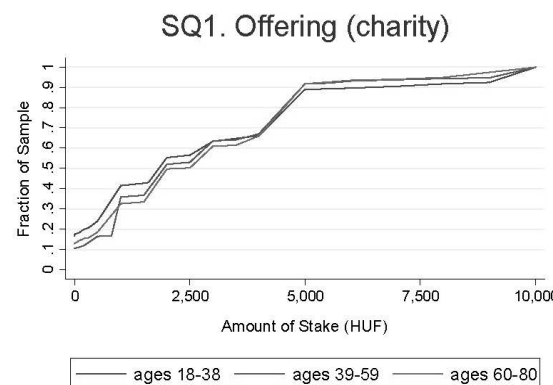

SQ3. Expectation

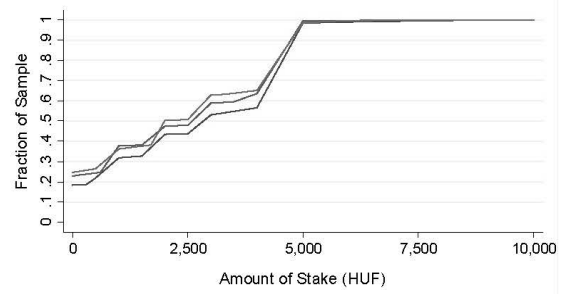

- ages $18-38-$ ages $39-59-$ ages $60-80$
SQ2. Offering (recipient)

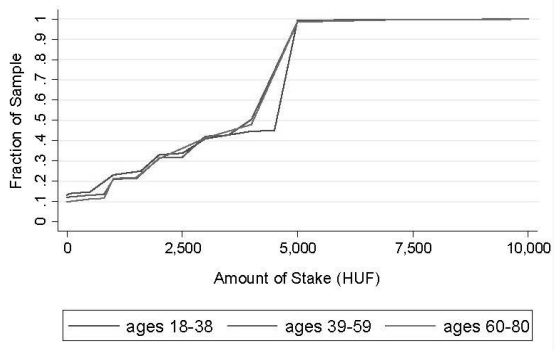

SQ4. Fair distribution

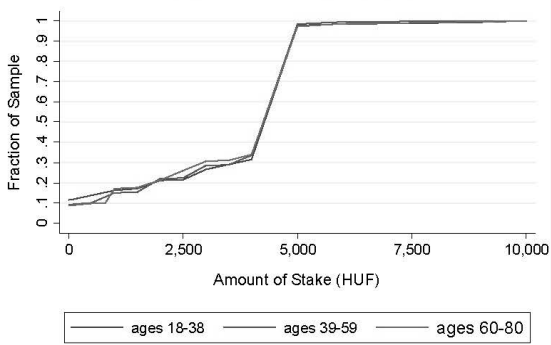

Source: own editing

Table 2. Pairwise comparisons of SQ2-SQ3 differences by age categories

\begin{tabular}{|c|c|c|}
\hline & SQ2-SQ3_2 & SQ2-SQ3_3 \\
\hline SQ2-SQ3_1 & 0.1666 & $0.0954 *$ \\
\hline SQ2-SQ3_2 & & 0.5831 \\
\hline
\end{tabular}

Note: p-values were corrected by the Bonferroni and Holm methods to control the familywise error rate. Table 2 contains the Holm-adjusted p-values of the SQ2-SQ3 differences by age categories. An extended analysis can be found in Appendix A. Supplementary material section (Table A.8).

${ }^{*} p<0.10,{ }^{* *} p<0.05,{ }^{* * *} p<0.01$

Source: own calculation

\section{DISCUSSION AND CONCLUSION}

While the dictator game is certainly the simplest experimental game, the abundance of relevant literature, the diversity of research objectives and experimental design, and the major differences in the evolution and interpretation of results suggest that previous experiments have far from exhausted the potential of this game. The problem of fairness and other-regarding preferences has been a defining factor of the experiments with dictator game from the onset, providing an obvious opportunity to 
examine certain components of pro-social behavior (norm of equality, altruism, generosity, etc.) (Fehr \& Schmidt 2006, Cooper \& Kagel 2015). The application of the typical experimental design, which eliminates the role of "property rights" (Hoffman et al. 1994, 1996, 2008, Smith 2010) and thus interprets the dictator game as a simple distribution task, has played a decisive role in the emergence of many new research findings.

Our study focused primarily on the experimental results of Brañas-Garza et al. (2017) that both dictator-decisions and expectations are based on generosity, and in a broader sense, on egalitarian behavior. The dominant role of hyper-fair behavior was supported by our results. In line with previous research findings, the modal answer for all dictator game questions was the equal split. Extremes, such as pure selfishness or overall generosity were identified in relatively few cases. We found significant differences across the dictator games in terms of the amounts of money marked by the respondents, rejecting our hypothesis that the four variants are stochastically the same in the total sample. According to the post-hoc analysis, the stochastic homogeneity does not exist in either meaningful variable comparison. Using several control variables, our model suggests that participants in the first three cases (charity-offering, recipient-offering, and expectation) give lower amounts on average compared to recipient-offerings and fairness, respectively. In contrast, the marked amounts are higher for recipient-offerings than for expectations.

Researches on the age-specific characteristics of decision-making and components of pro-social behavior in old age often refer to the importance of pro-social manifestations arising from the wisdom of old age. Despite the unbroken popularity of the dictator game for decades, research goals, and the diversity of the experimental design, the study of the specific aging characteristics of altruism or generosity is not one of the typical research goals of experiments conducted with this type of game (Lim \& Yu 2015). Analyses published since the findings of Engel's (2011) meta-study, which emphasizes some incredible degree of manifestations of generosity in old age (Roalf et al. 2012, Beadle et al. 2013, Rieger \& Mata 2015, Kettner \& Waichman 2016, Matsumoto et al. 2016, Ogawa et al. 2020), are only able to refute Engel's (2011) unusually strong statement. However, in other respects (role, direction, extent, and other characteristics of old age) there is no consensus among researchers. Because we worked with survey data of an age-representative sample, we attempted to explore the age-specific characteristics of the hypothetical dictator game. Based on the given results, we found diversity in the distributions of the variable-differences across the age categories in contrast to the individual variables, where the distributions were stochastically the same by the distinct age groups. A post-hoc analysis was used for the significant recipient offering and expectation difference. The stochastic homogeneity did not exist when the first age category was compared to the third. However, using control variables, our model showed that age has no special effect on the gap between recipient offerings, and expectations related to this. In the absence of any significant age-specific characteristics, our analysis seems to support the findings of Roalf et al. (2012) and Rieger \& Mata (2015).

12 Nagy Jeno utca, Pecs, H-7624, Hungary (email: szociograf@szociograf.hu)

2 Although the condition of sphericity is violated according to the Mauchly's test $(\chi 2(5, N=770)=396.41, p<.0001)$, this does not pose any particular problem, since circularity is not a prerequisite for the Friedman test.

3 Although the condition of sphericity is violated according to the Mauchly's test $(\chi 2(5, N=770)=396.41, p<.0001)$, this does not pose any particular problem, since circularity is not a prerequisite for the Friedman test.

4 The list of control variables can be found in Table A.3.

5 The composite dependent variable should only be interpreted as a marked amount, as it involves both offerings, expectations, and answers referring to fair distribution mixed at the same time.

6 No outlying data were identified with the $1.5 * I Q R$ rule for the dependent variable.

7 Dictator game variables are left-censored at 0 and right-censored at 10,000.

8 The SQ2-SQ3_1_3 dependent variable is left-censored at $-10,000$ and right-censored at 10,000. 


\section{REFERENCES}

Aguiar, F., Branas-Garza, P., Miller, L. M. (2008), "Moral distance in dictator games?", Judgment and Decision Making Journal, 3(4), 344-354

Ball, S., Eckel, C. (1998), "The economic value of status", Journal of Socio-Economics, 27(4), 495-514 DOI: 10.1016/s1053-5357(98)80004-8

Beadle, J. N., Sheehan, A. H., Dahlben, B., Gutchess, A. H. (2013), "Aging, empathy and prosociality", Journals of Gerontology, Series B: Psychological Sciences and Social Sciences, 70(2), 213-222 DOI: 10.1093/geronb/gbt091

Becker, G. S. (1974), "A theory of social interactions", Journal of Political Economy 82(6), 1063-1093 DOI: 10.1086/260265

Bohnet, I., Frey, B. (1999a), "The sound of silence in prisoner's dilemma and dictator games", Journal of Economic Behavior and Organization, 38(1), 43-57 DOI: 10.1016/s01672681(98)00121-8

Bohnet, I., Frey, B. (1999b), "Social distance and other-regarding behavior: Comment", American Economic Review, 89(1), 335-340 DOI: 10.1257/aer.89.1.335

Brañas-Garza, P. (2006), "Poverty in dictator games: Awakening solidarity", Journal of Economic Behavior \& Organization, 60(3), 306320 DOI: 10.1016/j.jebo.2004.10.005

Brañas-Garza, P., Capraro, V., Rascon-Ramirez, E. (2018), "Gender differences in altruism on Mechanical Turk: Expectations and actual behavior", Economics Letters, 170, 19-23 DOI: 10.1016/j.econlet.2018.05.022

Brañas-Garza, P., Rodríguez-Lara, I., Sánchez, A. (2017), "Humans expect generosity", Scientific Reports, 7(1) DOI: 10.1038/srep42446

Charness, G., Gneezy, U. (2008), "What's in a name? Anonymity and social distance in dictator and ultimatum games", Journal of Economic Behavior and Organization, 68(1), 88-103 DOI: 10.1016/j.jebo.2008.03.001

Cherry, T., Frykblom, P., Shogren, J. (2002), "Hard nose the dictator", American Economic Review, 92(4), 1218-1221

Cooper, D. J., Kagel, J. H. (2015), “Other-regarding preferences: A selective survey of experimental results", in: Kagel, J. H., Roth, A. E. (eds.), Handbook of Experimental Economics, Vol. 2, Princeton and Oxford: Princeton University Press, 217-289 DOI: 10.1515/9781400883172005

Eckel, C., Grossman, P. (1996), "Altruism in anonymous dictator games", Games and Eco- nomic Behavior, 16(2), 181-191 DOI: 10.1006/ game.1996.0081

Engel, C. (2011), "Dictator games: A meta study", Experimental Economics", 14(4), 583-610 DOI: 10.1007/s10683-011-9283-7

Falk, A., Becker, A., Dohmen, T., Enke, B., Huffman, D., Sunde, U. (2018), "Global Evidence on Economic Preferences", The Quarterly Journal of Economics, 133(4), 1645-1692 DOI: 10.1093/qje/qjy013

Fehr, E., Schmidt, K. M. (2006), "The economics of fairness, reciprocity and altruism: Experimental evidence and new theories", in: Kolm S.-C. \& Ythier J. M. (eds.), Handbook of the economics of giving, altruism and reciprocity, Amsterdam: Elsevier, Vol. 1, 615-691 DOI: 10.1016/s15740714(06)01008-6

Forsythe, R., Horowitz, J., Savin, N. E., Sefton, M. (1994), "Replicability, fairness and pay in experiments with simple bargaining games", Games and Economic Behavior, 6(3), 347-369.

Güth, W., Schmittberger, R., Schwartze, B. (1982), "An experimental analysis of ultimatum bargaining", Journal of Economic Behavior and Organization, 3(4), 367-388 DOI: 10.1016/0167-2681(82)90011-7

Harbaugh, W. (1998), "The prestige motive for making charitable transfers", American Economic Review, 88(2), 277-282

Hoffman, E., McCabe, K., Shachat, K., Smith, V. L. (1994), "Preferences, property rights, and anonymity in bargaining games", Games and Economic Behavior, 7(3): 346-380 DOI: $10.1006 /$ game.1994.1056

Hoffman, E., McCabe, K., Smith, V. L. (1996), "Social distance and other-regarding behavior in dictator games", American Economic Review, 86(3), 653-660

Hoffman, E., McCabe, K., Smith, V. L. (2008), "Preferences and property rights in ultimatum and dictator games", in: Plott, C. R., Smith, V. L. (eds.), Handbook of Experimental Economics Results, Oxford: North Holland, Vol. 1, 417-422

Kahneman, D., Knetsch, J., Thaler, R. (1986), "Fairness and the assumptions of economics", The Journal of Business, 59(4), 285-300 DOI: 10.1086/296367

Kettner, S. E., Waichman, I. (2016), "Old age and prosocial behavior: Social preferences or experimental confounds?" Journal of Economic Psychology, 53, 118-130 DOI: 10.1016/j. joep.2016.01.003

Lim, K. T. K., Yu, R. (2015), "Aging and wisdom: Age-related changes in economic and social decision making", Frontiers in Aging 
Neuroscience, 7(120), 1-11 DOI: 10.3389/ fnagi.2015.00120

Matsumoto, Y., Yamagishi, T., Li, Y., Kiyonari, T. (2016), "Prosocial behavior increases with age across five economic games", PLoS ONE, 11(7), 1-16 DOI: 10.1371/journal.pone. 0158671

Meeks, T. W., Jeste, D. V. (2009), "Neurobiology of wisdom: A literature overview", Arch Gen Psychiatry, 66(4), 355-365 DOI: 10.1001/archgenpsychiatry.2009.8

Ogawa, K., Kawamura, T., Matsushita, K. (2020), "Effects of cognitive ability and age on giving in dictator game experiments", Research in Economics, 74(4), 323-335 DOI: 10.1016/j. rie. 2020.10 .002

Oxoby, R., Spraggon, J. (2008), "Mine and yours: Property rights in dictator games", Journal of Economic Behavior and Organization, 65(3-4), 703-713 DOI: 10.1016/j.jebo.2005.12.006
Pereda, M., Brañas-Garza, P., Rodríguez-Lara, I., Sánchez, A. (2017), “The emergence of altruism as a social norm", Scientific Reports, 7, 9684 DOI: 10.1038/s41598-017-07712-9

Rieger, M., Mata, R. (2015), "On the generality of age differences in social and nonsocial decision making", Journals of Gerontology, Series B: Psychological Sciences and Social Sciences, 70(2), 200-212 DOI: 10.1093/geronb/gbt088

Roalf, D. R., Mitchell, S. H., Harbaugh, W. T., Janowsky, J. S. (2012), "Risk, reward and economic decision making in aging", The Journals of Gerontology, Series B: Psychological Sciences and Social Sciences, 67(3), 289-298 DOI: $10.1093 /$ geronb/gbr099

Smith, V. L. (2010), "Theory and experiment: What are the questions?", Journal of Economic Behavior and Organization, 73(1), 3-15 DOI: 10.1016/j.jebo.2009.02.008

\section{Zoltan Szabo, PhD, Associate Professor szabo.zoltan@ktk.pte.hu University of Pecs, Faculty of Business and Economics, \\ Department of Finance and Accounting \\ Oliver Bela Kovacs, PhD Student University of Pecs, Faculty of Business and Economics, Department of Economics and Econometrics \\ Gabor Murai, PhD Student University of Pecs, Faculty of Business and Economics, Department of Economics and Econometrics \\ Zsofia Voros, Senior Research Fellow University of Pecs, Faculty of Business and Economics, \\ Department of Finance and Accounting \\ Daniel Kehl, PhD, Assistant Professor University of Pecs, Faculty of Business and Economics, Department of Economics and Econometrics}




\section{APPENDIX}

A. Supplementary material

\section{Dataset A.1}

Dataset A.2

Dataset A.3

Dataset A.4

Table A.1. Descriptive statistics of survey questions referring to dictator games

\begin{tabular}{|l|l|l|l|l|l|l|l|l|l|}
\hline Variable & N & Min & Max & Mean & Median & $\begin{array}{l}\text { Std. } \\
\text { Dev. }\end{array}$ & Variance & Skewness & Kurtosis \\
\hline SQ1 & 770 & 0 & 10000 & 3000 & 2000 & 2654 & 7045194 & 1.023 & 0.618 \\
\hline SQ2 & 770 & 0 & 10000 & 3465 & 5000 & 1948 & 3792644 & -0.518 & -0.715 \\
\hline SQ3 & 770 & 0 & 10000 & 2771 & 3000 & 2117 & 4483022 & 0.063 & -1.132 \\
\hline SQ4 & 770 & 0 & 10000 & 3958 & 5000 & 1871 & 3499779 & -0.881 & 0.467 \\
\hline
\end{tabular}

Source: own calculation

Table A.2. Shapiro-Wilk W test for normality by dictator game survey questions

\begin{tabular}{|l|l|l|l|l|l|}
\hline Variable & $\mathbf{N}$ & $\mathbf{W}$ & $\mathbf{V}$ & $\mathbf{z}$ & Prob>z \\
\hline SQ1 & 770 & 0.92147 & 39.046 & 8.977 & $0.0000^{* * *}$ \\
\hline SQ2 & 770 & 0.96262 & 18.587 & 7.159 & $0.0000^{* * *}$ \\
\hline SQ3 & 770 & 0.95559 & 17.110 & 6.956 & $0.0000^{* * *}$ \\
\hline SQ4 & 770 & 0.94205 & 28.813 & 8.233 & $0.0000^{* * *}$ \\
\hline
\end{tabular}

" $p<0.10,{ }^{* *} p<0.05,{ }^{* * *} p<0.01$

Source: own calculation

Table A.3. List of control variables

\begin{tabular}{|l|l|l|}
\hline Variable name & Type & Code/description \\
\hline gender & binary categorical & 1: female; 0: male \\
\hline age & scale & age \\
\hline pph & scale & persons per household \\
\hline education_cat_2_d & binary categorical & 1: secondary vocational education; 0: otherwise \\
\hline education_cat_3_d & binary categorical & 1: high-school graduation; 0: otherwise \\
\hline education_cat_4_d & binary categorical & 1: higher education degree; 0: otherwise \\
\hline net_income_pph_cat_2_d & binary categorical & $\begin{array}{l}\text { 1: between 32,001 and 65,000 HUF/month; } \\
\text { 0: otherwise }\end{array}$ \\
\hline net_income_pph_cat_3_d & binary categorical & $\begin{array}{l}\text { 1: between } 65,001 \text { and 90,000 HUF/month; } \\
\text { 0: otherwise }\end{array}$ \\
\hline net_income_pph_cat_4_d & binary categorical & $\begin{array}{l}\text { 1: between 90,001 and 114,000 HUF/month; } \\
\text { 0: otherwise }\end{array}$ \\
\hline
\end{tabular}




\begin{tabular}{|l|l|l|}
\hline net_income_pph_cat_5_d & binary categorical & $\begin{array}{l}\text { 1: between 114,001 and 158,000 HUF/month; } \\
\text { 0: otherwise }\end{array}$ \\
\hline net_income_pph_cat_6_d & binary categorical & 1: more than 158,001 HUF/month; 0: otherwise \\
\hline
\end{tabular}

Note: binary categorical variables education_cat_1_d (grade school) and net_income_pph_cat_1_d (less than 32,000 HUF/month) are the base categories.

Source: own editing

Table A.4. Summary of multiple linear regression analysis

\begin{tabular}{|c|c|c|c|c|c|c|c|}
\hline \multirow{2}{*}{ Model } & & B & SEB & $\mathrm{t}$ & $\mathrm{p}$ & R2 & Adj. R2 \\
\hline & & & & & & 0.0629 & 0.0572 \\
\hline & (Constant) & 1721.2030 & 387.3188 & 4.44 & $0.000 * * *$ & & \\
\hline & SQ2_d & 430.4017 & 122.1159 & 3.52 & $0.000 * * *$ & & \\
\hline & SQ3_d & -210.1128 & 122.1159 & -1.72 & $0.085^{*}$ & & \\
\hline & SQ4_d & 930.7419 & 122.1159 & 7.62 & $0.000 * * *$ & & \\
\hline & gender & -45.7659 & 88.9801 & -0.51 & 0.607 & & \\
\hline & age & 0.1836 & 2.9720 & 0.06 & 0.951 & & \\
\hline & pph & 64.9694 & 41.0448 & 1.58 & 0.114 & & \\
\hline & education_cat_2_d & 420.2641 & 145.1645 & 2.90 & $0.004 * * *$ & & \\
\hline & education_cat_3_d & 264.7141 & 141.1253 & 1.88 & $0.061 *$ & & \\
\hline & education_cat_4_d & 270.8877 & 180.2274 & 1.50 & 0.133 & & \\
\hline & net_income_pph_cat_2_d & 398.3134 & 315.6696 & 1.26 & 0.207 & & \\
\hline & net_income_pph_cat_3_d & 807.7866 & 308.8894 & 2.62 & $0.009 * * *$ & & \\
\hline & net_income_pph_cat_4_d & 757.6025 & 318.6046 & 2.38 & $0.017 * *$ & & \\
\hline & net_income_pph_cat_5_d & 1089.2860 & 306.9837 & 3.55 & $0.000 * * *$ & & \\
\hline & net_income_pph_cat_6_d & 1091.8300 & 311.5536 & 3.50 & $0.000 * * *$ & & \\
\hline
\end{tabular}

Note: Model F $(14,2325)=11.14, p<.0001$.

${ }^{*} p<0.10,{ }^{* *} p<0.05,{ }^{* * *} p<0.01$

Source: own calculation

Table A.5. Summary of multiple linear regression analysis using heteroscedasticity-robust standard errors

\begin{tabular}{lllllll} 
& & $B$ & $R S E B$ & $t$ & $p$ & $R^{2}$ \\
\hline Model & & & & & & 0.0629 \\
& (Constant) & 1721.2030 & 407.0267 & 4.23 & $0.000^{* * *}$ & \\
& SQ2_d & 430.4017 & 132.9182 & 3.24 & $0.001^{* * *}$ & \\
& SQ3_d & -210.1128 & 136.6744 & -1.54 & 0.124 & \\
& SQ4_d & 930.7419 & 129.8092 & 7.17 & $0.000^{* * *}$ & \\
& gender & -45.7659 & 89.2279 & -0.51 & 0.608 & \\
& age & 0.1836 & 3.0004 & 0.06 & 0.951 &
\end{tabular}

16 MARKETING \& MENEDZSMENT 2021. KÜLÖNSZÁM 2. Időskori pénzügyi és befektetési döntések 


$\begin{array}{lllll}\text { pph } & 64.9694 & 41.6646 & 1.56 & 0.119 \\ \text { education_cat_2_d } & 420.2641 & 141.9266 & 2.96 & 0.003^{* * *} \\ \text { education_cat_3_d } & 264.7141 & 138.5644 & 1.91 & 0.056^{*} \\ \text { education_cat_4_d } & 270.8877 & 174.7214 & 1.55 & 0.121 \\ \text { net_income_pph_cat_2_d } & 398.3134 & 338.4649 & 1.18 & 0.239 \\ \text { net_income_pph_cat_3_d } & 807.7866 & 329.9997 & 2.45 & 0.014^{* *} \\ \text { net_income_pph_cat_4_d } & 757.6025 & 337.1658 & 2.25 & 0.025^{* *} \\ \text { net_income_pph_cat_5_d } & 1089.2860 & 325.6020 & 3.35 & 0.001^{* * *} \\ \text { net_income_pph_cat_6_d } & 1091.8300 & 327.8405 & 3.33 & 0.001^{* * *}\end{array}$

Note: Model $F(14,2325)=13.26, p<.0001$.

${ }^{*} p<0.10,{ }^{* *} p<0.05,{ }^{* * *} p<0.01$

Source: own calculation

Table A.6. Summary of Tobit regression analysis using heteroscedasticity-robust standard errors

\begin{tabular}{|c|c|c|c|c|c|c|}
\hline & & $B$ & $R S E B$ & $t$ & $p$ & $\begin{array}{l}\text { Pseudo } \\
R^{2}\end{array}$ \\
\hline \multirow[t]{16}{*}{ Model } & & & & & & 0.0039 \\
\hline & (Constant) & 1383.5260 & 484.9117 & 2.85 & $0.004 * * *$ & \\
\hline & SQ2_d & 421.3583 & 152.7378 & 2.76 & $0.006 * * *$ & \\
\hline & SQ3_d & -348.1478 & 162.7645 & -2.14 & $0.033 * *$ & \\
\hline & SQ4_d & 955.2347 & 148.2250 & 6.44 & $0.000 * * *$ & \\
\hline & gender & -41.6729 & 103.3619 & -0.40 & 0.687 & \\
\hline & age & 0.2436 & 3.4792 & 0.07 & 0.944 & \\
\hline & $\mathrm{pph}$ & 81.3171 & 47.7016 & 1.70 & $0.088 *$ & \\
\hline & education_cat_2_d & 453.8467 & 166.3503 & 2.73 & $0.006 * * *$ & \\
\hline & education_cat_3_d & 261.8690 & 163.1700 & 1.60 & 0.109 & \\
\hline & education_cat_4_d & 301.2841 & 201.4712 & 1.50 & 0.135 & \\
\hline & net_income_pph_cat_2_d & 452.6162 & 417.3564 & 1.08 & 0.278 & \\
\hline & net_income_pph_cat_3_d & 933.3399 & 406.7186 & 2.29 & $0.022 * *$ & \\
\hline & net_income_pph_cat_4_d & 903.8198 & 415.4737 & 2.18 & $0.030 * *$ & \\
\hline & net_income_pph_cat_5_d & 1309.1990 & 401.7928 & 3.26 & $0.001 * * *$ & \\
\hline & net_income_pph_cat_6_d & 1299.0130 & 404.2715 & 3.21 & $0.001 * * *$ & \\
\hline
\end{tabular}

311 left-censored observations at C_SQ $\leq 0$

1991 uncensored observations

38 right-censored observations at C_SQ $\geq 10000$

Note: Model F $(14,2326)=12.15, p<.0001$.

${ }^{*} p<0.10,{ }^{* *} p<0.05,{ }^{* * *} p<0.01$

Source: own calculation 
Table A.7. James' second-order approximation tests on ranked dictator game survey questions and variable differences by age categories

\begin{tabular}{|l|l|l|l|l|l|}
\hline \multicolumn{2}{|l|}{ Ranked variables } & \multicolumn{4}{l|}{ Ranked variable differences } \\
\hline Variable & Wald chi2 & Prob $>$ chi2 & Variable & Wald chi2 & Prob > chi2 \\
\hline SQ1_rank & $\mathrm{X} 2(2)=0.58$ & 0.7490 & SQ1_rank-SQ2_rank & $\mathrm{X}^{2}(2)=1.05$ & 0.5925 \\
\hline SQ2_rank & $\mathrm{X} 2(2)=0.41$ & 0.8147 & $\mathrm{SQ} 2$ rank-SQ3_rank & $\mathrm{X}^{2}(2)=4.75$ & $0.0946^{*}$ \\
\hline SQ3_rank & $\mathrm{X} 2(2)=4.24$ & 0.1217 & $\mathrm{SQ} 2$ rank-SQ4_rank & $\mathrm{X}^{2}(2)=0.47$ & 0.7920 \\
\hline SQ4_rank & $\mathrm{X} 2(2)=0.14$ & 0.9317 & $\mathrm{SQ}$ 3_rank-SQ4_rank & $\mathrm{X}^{2}(2)=3.08$ & 0.2158 \\
\hline
\end{tabular}

$* p<0.10, * * p<0.05, * * * p<0.01$

Source: own editing

Table A.8. Bonferroni- and Holm-adjusted p-values of SQ2-SQ3 differences in a comparison of age categories

\begin{tabular}{|l|l|l|l|}
\hline Variable-pair & $\mathbf{p}$ & Bonferroni $\mathbf{p}$ & Holm $\mathbf{p}$ \\
\hline $\begin{array}{l}\text { SQ2-SQ3_1 } \\
\text { SQ2-SQ3_2 }\end{array}$ & $0.0833^{*}$ & 0.2499 & 0.1666 \\
\hline $\begin{array}{l}\text { SQ2-SQ3_1 } \\
\text { SQ2-SQ3_3 }\end{array}$ & $0.0318^{* *}$ & $0.0954 * *$ & $0.0954 *$ \\
\hline $\begin{array}{l}\text { SQ2-SQ3_2 } \\
\text { SQ2-SQ3_3 }\end{array}$ & 0.5831 & 1.0000 & 0.5831 \\
\hline
\end{tabular}

$* \mathrm{p}<0.10, * * \mathrm{p}<0.05, * * * \mathrm{p}<0.01$

Source: own calculation

Table A.9. Summary of Tobit regression analysis on SQ2-SQ3 difference using heteroscedasticity-robust standard errors

\begin{tabular}{|c|c|c|c|c|c|c|}
\hline & & $B$ & $R S E B$ & $t$ & $p$ & $\begin{array}{l}\text { Pseudo } \\
R 2\end{array}$ \\
\hline \multirow[t]{11}{*}{ Model } & & & & & & 0.0030 \\
\hline & (Constant) & 1284.4040 & 692.8816 & 1.85 & $0.065^{*}$ & \\
\hline & age_cat_1_3_d & -134.4856 & 214.9790 & -0.63 & 0.532 & \\
\hline & gender & 353.8986 & 177.2083 & 2.00 & $0.047 * *$ & \\
\hline & pph & -139.0778 & 90.4459 & -1.54 & 0.125 & \\
\hline & education_cat_2_d & 53.0841 & 241.4219 & 0.22 & 0.826 & \\
\hline & education_cat_3_d & 295.7309 & 230.6799 & 1.28 & 0.201 & \\
\hline & education_cat_4_d & 698.0662 & 349.9241 & 1.99 & $0.047 * *$ & \\
\hline & net_income_pph_cat_2_d & -224.1530 & 669.0477 & -0.34 & 0.738 & \\
\hline & net_income_pph_cat_3_d & -452.8002 & 677.4898 & -0.67 & 0.504 & \\
\hline & net_income_pph_cat_4_d & -518.2937 & 722.3018 & -0.72 & 0.474 & \\
\hline
\end{tabular}




\begin{tabular}{rrrrr} 
net_income_pph_cat_5_d & -851.8961 & 692.2752 & -1.23 & 0.219 \\
net_income_pph_cat_6_d & -760.7517 & 702.2942 & -1.08 & 0.279 \\
\hline
\end{tabular}

0 left-censored observations

358 uncensored observations

0 right-censored observations

Note: Model $F(11,347)=1.74, p=.0644$.

${ }^{*} p<0.10,{ }^{* *} p<0.05,{ }^{* * *} p<0.01$

Source: own calculation 